\title{
Porphyromonas somerae
}

National Cancer Institute

\section{Source}

National Cancer Institute. Porphyromonas somerae. NCI Thesaurus. Code C86659.

A species of obligately anaerobic, Gram-negative, rod shaped bacteria assigned to the phylum Bacteroidetes. This species is nonmotile, non-spore forming, beta- $\mathrm{N}$-acetylglucosaminidase positive, indole, catalase, lipase, alpha-fucosidase, and trypsin negative, pigmented, weakly saccharolytic, and does not reduce nitrate or hydrolyze starch or esculin. P. somerae is associated with chronic foot infections in individuals with diabetes or vascular disease. 